\title{
GERENCIAMENTO DE RESULTADOS EM INSTITUIÇÕES FINANCEIRAS NO BRASIL: UMA ANÁLISE COM BASE EM PROVISÕES PARA CRÉDITO DE LIQUIDAÇÃO DUVIDOSA ${ }^{1}$
}

\author{
EARNINGS MANAGEMENT BY FINANCIAL INSTITUTIONS IN BRAZIL: \\ AN ANALYSIS BASED ON LOAN LOSS PROVISIONS \\ Marcelo Alvaro da Silva Macedo ${ }^{2}$ \\ Pós-Doutor em Controladoria e Contabilidade pela FEA-USP \\ Professor do Programa de Pós-Graduação em Ciências Contábeis da UFRJ \\ malvaro.facc.ufrj@gmail.com \\ Vera Lúcia de Aguiar Kelly \\ Mestra em Ciências Contábeis pela UFRJ \\ verapa@uol.com.br
}

\section{RESUMO}

Este artigo tem como objetivo analisar os indícios de gerenciamento de resultados pelas instituições financeiras que operam no mercado brasileiro, por meio do uso das provisões para crédito de liquidação duvidosa (PCLD) como accruals específicos, no período de 2006 a 2012, tendo como foco a presença de capital estrangeiro. Para tanto, utilizou-se a análise de regressão com dados em pooled das 50 maiores instituições financeiras, considerando a PCLD como variável dependente e o volume de operações de crédito (CRED), o resultado antes da PCLD e o IR (LL) e a presença de capital estrangeiro (ESTR) como variáveis independentes. De maneira geral, os resultados mostram que, conforme esperado, um aumento do volume de operações de crédito e arrendamento mercantil explica um aumento das provisões para créditos de liquidação duvidosa. Mais especificamente em relação ao indício de gerenciamento de resultado, observou-se que existem indícios de que a formação da provisão para créditos de liquidação duvidosa esteja sendo influenciada pelo nível de lucro. Isso porque a PCLD se mostra maior em instituições financeiras que apresentaram maiores valores para o lucro antes da PCLD e do IR e se mostra menor em instituições que apresentam menores valores para o lucro antes da PCLD e do IR. Por fim, percebe-se que os resultados encontrados mostram que os bancos com capital nacional possuem uma relação menor entre a PCLD e o desempenho (Lucro). Isso indica que existem indícios de maiores práticas de gerenciamento de resultados com o uso da PCLD em bancos com capital estrangeiro.

Palavras-chave: Modelo de Accruals Específicos; PCLD; Instituições Financeiras; Gerenciamento de Resultado.

\footnotetext{
${ }^{1}$ Artigo recebido em: 21/06/2016. Revisado por pares em: 04/08/2016. Versão final recebida em: 28/08/2016. Recomendado para publicação em: 28/08/2016 por Luiz Felipe de Araújo Pontes Girão (Editor Adjunto). Publicado em: 30/08/2016. Organização responsável pelo periódico: UFPB.

2 Endereço: Av. Pasteur, 250, Sala 250, LEDO/FACC/UFRJ, Urca, CEP 22.290-240, Rio de Janeiro/RJ.

DOI: http://dx.doi.org/10.18405/recfin20160206
} 


\section{ABSTRACT}

This article aims to analyze the evidence of earnings management by financial institutions operating in the Brazilian market, due to the use of loan loss provisions (PCLD) as specific accruals, from 2006 to 2012 , focusing on the presence of foreign capital. Therefore, we use regression analysis with pooled data of the 50 largest financial institutions, considering PCLD as dependent variable and the volume of loans (CRED), income before PCLD and taxes (LL) and the presence of foreign capital (ESTR) as independent variables. Overall, the results show that, as expected, an increase in the volume of loans and lease explains an increase in loan loss provisions. More specifically in relation to the evidence of earnings management, it was observed that there are signs that the level of profit can explain the decision of the level of the loan loss provisions. This is because the PCLD shows higher values in financial institutions that had higher values for income before PCLD and taxes and shows lower values in institutions that have lower values for income before PCLD and taxes. Finally, the results show that banks with national capital have a lower relationship between the PCLD and performance (LL). This indicates that there is evidence of greater earnings management practices using the PCLD in banks with foreign capital.

Keywords: Specific Accruals Model; Loan Loss Provisions; Financial Institution; Earnings Management.

\section{INTRODUÇÃO}

A informação contábil relaciona-se aos objetivos da contabilidade de mensurar o conjunto de eventos econômicos e comunicar os resultados das entidades às partes interessadas, constituindo um de seus produtos. Isso porque a contabilidade tem como objetivo mensurar e comunicar o conjunto de eventos econômicos relacionados aos resultados das entidades (YAMAMOTO; SALOTTI, 2006). O CPC-00 - Pronunciamento Conceitual Básico - destaca que as informações são úteis quando podem influenciar as decisões econômicas dos usuários, ajudando-os a avaliar o impacto de eventos passados, presentes ou futuros ou confirmando ou corrigindo as suas avaliações anteriores (CPC, 2011). Porém, para que a mesma seja útil aos usuários é necessário que a mesma seja confiável. Assim sendo, surge a discussão sobre o Gerenciamento da Informação Contábil ou de Resultados. Segundo Cardoso (2005) e Rodrigues (2008) o Gerenciamento da Informação Contábil ou de Resultados consiste no fato dos gestores utilizarem critérios discricionários (escolhas contábeis ou operacionais) para alterar as informações constantes das demonstrações financeiras, com o intuito de modificar, ao seu interesse, a real situação econômico-financeira da entidade.

De acordo com Martinez (2001) e Paulo (2007), o gerenciamento de resultados pode ser, então, entendido como o juízo de valor, que ocorre sem a violação das normas contábeis e que pode ser influenciado pela situação econômico-financeira que a empresa apresentar no momento da divulgação das Demonstrações Financeiras. Ou seja, em momentos de maus resultados é possível que se gerencie os accruals para que a empresa disfarce seu desempenho aquém das expectativas, mas em momentos de superação das expectativas é possível que os gestores façam escolhas contábeis ou operacionais para reduzir o resultado a ser reportado, de modo que o resultado se mostre mais estável (alisamento de resultados).

Este problema remete à Teoria da Agência, pois de acordo com Holanda e Coelho (2013) o problema básico de qualquer relação de agência reside na possibilidade de o agente assumir um comportamento oportunista. Nesta perspectiva, a informação contábil de qualidade poderá ser importante ferramenta para monitorar conflitos de agência, ao transmitir com eficiência a situação econômica das firmas aos acionistas e investidores atuais e potenciais. Por outro lado, informação contábil com menor qualidade pode acobertar atitudes oportunísticas dos gestores das firmas, em prejuízo dos demais stakeholders. 
Dentre as escolhas e julgamentos que podem ser feitos e que impactam a informação financeira (mais especificamente o resultado contábil) está o nível de provisão para créditos de liquidação duvidosa (PCLD). De acordo com Dantas et al. (2013), essas provisões representam, de modo geral, os maiores accruals das instituições financeiras, desempenhando papel fundamental nas decisões dos gestores sobre eventuais manipulações contábeis. Além disso, esta crença faz com que a PCLD seja o principal alvo dos reguladores em termos de manipulações das informações contábeis. Estes argumentos são reforçados por Goulart (2007) que defende que há maior discricionariedade sobre as acumulações correntes, como é o caso da PCLD. Isso porque, de acordo com Cunha et al. (2009) em face do julgamento presente na classificação do risco das operações de créditos e, por conseguinte, na constituição da PCLD, verifica-se a possibilidade do uso da discricionariedade por parte dos gestores de instituições financeiras.

Cabe ressaltar que alguns autores, tais como, Holanda e Coelho (2013), Maria Jr, Maria e Vargas (2013) e Silva et al. (2014) ressaltam que a participação de capital estrangeiro poderia funcionar como incentivo a redução do gerenciamento de resultados, por conta da demanda por informações de maior qualidade. Neste contexto, o presente estudo procura responder as seguintes questões de pesquisa: quais os indícios de uso das provisões para crédito de liquidação duvidosa (PCLD) no gerenciamento de resultados de instituições financeiras no Brasil? Existe a influência do capital estrangeiro nesse gerenciamento?

Neste sentido, tem-se, então, o objetivo de analisar os indícios de gerenciamento de resultados pelas instituições financeiras que operam no mercado brasileiro por meio do uso das provisões para crédito de liquidação duvidosa (PCLD) como accruals específicos, no período de 2006 a 2012, tendo como foco a influência do capital estrangeiro nesse gerenciamento.

\section{QUALIDADE DA INFORMAÇÃO CONTÁBIL E GERENCIAMENTO DE RESULTADO}

De acordo com Yamamoto e Salotti (2006), a informação contábil é considerada útil quando é capaz de alterar o estado da arte do conhecimento do seu usuário em relação à empresa, pois a partir de interpretações, ele a utiliza na solução de problemas. Ball e Brown (2014) ponderam que a utilidade das informações demanda respostas para perguntas como "úteis para quem?", "úteis com que propósito?"; e comentam que a atribuição de significado dos números contábeis surge de seu uso em determinado contexto.

Segundo o Comitê de Pronunciamentos Contábeis (CPC, 2011), o objetivo dos relatórios financeiros é fornecer informações que sejam uteis a investidores existentes e em potencial e a credores. Dentre outros elementos, a informação contábil deve contribuir para a redução da assimetria informacional existente entre os usuários internos (gestores, executivos etc.) e os usuários externos da empresa (acionistas, credores etc.) (MACHADO; MACEDO; MACHADO, 2011).

De acordo com Almeida (2010) os benefícios econômicos atuais e potenciais gerados pelas empresas são divulgados aos agentes econômicos por meio das demonstrações financeiras. Assim, a informação contábil se mostra como importante canal de comunicação entre a empresa e os diversos agentes do mercado, se for capaz de apresentar conteúdo informacional que reflita a realidade econômica da empresa. Uma perspectiva relevante das mais recentes discussões sobre qualidade das informações contábeis é o impacto de aspectos relacionados ao mercado, tais como o grau de competição das firmas, na relevância da informação contábil. Muitos autores, dentre os quais destaca-se Haw et al (2004), Marciukaityte e Park (2009) e Almeida (2010) têm discutido que um grau elevado de competição pode trazer incentivos a publicação de informações contábeis de maior qualidade, funcionando como disciplinador do comportamento oportunístico dos gestores na utilização das escolhas contábeis e gerando assim demonstrações financeiras mais fidedígmas em relação à realidade econômica das empresas. 
Essa ideia se encontra reforçada nas palavras de Oliveira et al (2008), que enfatizam que é necessário que as informações contábeis sejam fiéis aos fatos, bem como transparentes, caracterizando dessa forma, neutralidade dos responsáveis em prover as mesmas. Neste sentido, o Gerenciamento de Resultados, definido pelos mesmos autores como sendo a alteração proposital dos resultados contábeis, visando atender à motivação particular, pode prejudicar a qualidade e, por conseguinte, a utilidade da informação contábil. Isso porque a prática do gerenciamento de resultado, por meio da manipulação das informações, fere o objetivo da contabilidade de gerar informações úteis, claras, transparentes e fidedignas (MATSUMOTO; PARREIRA, 2007).

De acordo com Barth, Landisman e Lang (2008) a qualidade da informação contábil pode ser detectada por meio da investigação de práticas de gerenciamento de resultados, visto que a associação entre os dois é inversa, ou seja, uma maior qualidade da informação contábil está associada a uma menor prática de gerenciamento de resultados. Paulo, Martins e Corrar (2007), Matsumoto e Parreira (2007) e Decourt, Martinewski e Pietro Neto (2007) ressaltam que a existência de critérios múltiplos nas normas e práticas contábeis possibilita aos administradores escolher alternativas válidas e legais com o objetivo de apresentar informações da forma desejada, conforme os interesses dos administradores, impactando o desempenho ou a estrutura financeira da empresa. Isso porque os gestores podem utilizar ações discricionárias para alterar a interpretação da realidade econômica e financeira da empresa.

Segundo Martinez (2001), a prática do gerenciamento de resultados não pode ser caracterizada como fraude, em virtude das escolhas realizarem-se dentro dos limites previstos nas normas contábeis, exatamente nos pontos em que estas normas facultam certa discricionariedade para o gestor, que utilizando-se da flexibilidade e subjetividade de julgamentos, realiza suas escolhas não em função do que dita a realidade concreta dos negócios, mas em função de outros incentivos, dentre os quais o de tornar o resultado mais estável por meio do alisamento do resultado.

De acordo com Fuji (2004) há situações que podem propiciar alisamento de resultados. Quando os lucros estão um pouco acima ou abaixo do que têm sido ao longo do tempo ou do alvo/planejado ou ainda quando os lucros apresentam volatilidade decorrente de eventos extraordinários, os gestores tendem a suavizar os resultados, ou seja, reduzir a volatilidade de lucros para evitar que tal variação seja interpretada como aumento de risco da firma. Esta ideia é reforçada pelas palavras de Goulart (2007), que ressalta que no caso de operações de crédito, quando o lucro (excluído o efeito da despesa de PCLD) aumenta, tem-se a expectativa que a PCLD atue no sentido de reduzi-lo; se o lucro cai, pode-se postergar o registro de provisões, de maneira que a PCLD impacte o resultado de forma menos adversa relativamente a períodos anteriores, podendo contribuir até para mitigar a queda; cumpre-se, assim, com o papel de suavização do resultado contábil final.

Neste sentido, Martinez (2001) destaca alguns objetivos para o gerenciamento de resultados: alcançar os resultados esperados pela administração; melhorar a imagem da situação econômicofinanceira da empresa, com o intuito de atrair mais investidores; e atender aos desejos econômicos dos acionistas, por maior distribuição de dividendos, por exemplo. Sendo assim, ainda de acordo com Martinez (2001), vê-se que as motivações para o gerenciamento da informação contábil são inúmeras e existem devido a pressões internas e externas à instituição. Cabe ressaltar que apesar de não constituir necessariamente um ato ilícito, o gerenciamento da informação contábil é uma forma de deturpação da realidade econômica da empresa.

No que se refere às formas de gerenciamento, Paulo (2007) cita: (i) o uso dos accruals discricionários; (ii) as alterações nas atividades operacionais; (iii) a manipulação classificatória dos elementos das demonstrações contábeis; (iv) e a manipulação por mensuração indevida dos elementos patrimoniais, principalmente os do Balanço Patrimonial. No caso da presente pesquisa, investiga-se 
o gerenciamento da informação contábil por meio de accruals discricionários específicos, que segundo Cardoso (2005) pode ocorrer a partir da escolha do momento do reconhecimento do elemento e/ou da escolha do critério de mensuração contábil.

Rodrigues (2008) define accruals (acumulações ou acréscimos) como a diferença entre lucro e o fluxo de caixa, ou seja, os valores que entram no cômputo da apuração do resultado contábil, mas que não impactam o caixa no presente (provisões, depreciações etc.). Neste sentido, Martinez (2008) ressalta que não há nada de errado no registro de accruals, pois seu uso serve para que se possa apurar o lucro no seu sentido econômico, como sendo o acréscimo efetivo na riqueza patrimonial da unidade econômica, independentemente da movimentação financeira. O problema, destaca Martinez (2008), está no fato do gestor de maneira discricionária aumentar ou diminuir esses accruals com o objetivo de influenciar o lucro.

Segundo Rodrigues (2008), acerca do gerenciamento de resultados ou da informação contábil, cabe ressaltar, a existência de três principais abordagens metodológicas empregadas por essa linha de pesquisa:

- Análise de Distribuição de Frequência: é empregada para detectar o gerenciamento da informação contábil ao redor de certos pontos de referência;

- Análise de Accruals Agregados: busca medir o grau de discricionariedade dos diretores das empresas sobre a informação reportada;

- Análise de Accruals Específicos: busca a análise do grau de discricionariedade dos diretores das empresas através do estudo de contas específicas.

O trabalho com foco em contas ou segmentos específicos de empresas demanda base de dados mais detalhada e conhecimento institucional sobre o setor analisado. Por isso tem sido comum, entre os pesquisadores brasileiros, o emprego do procedimento metodológico de acumulações específicas no estudo de bancos como é o caso de Fuji (2004) e Goulart (2007).

$\mathrm{Na}$ análise de acumulações específicas são utilizadas técnicas estatísticas de correlação e regressão podendo-se adotar, como procedimento de pesquisa:

- A utilização de modelo para estimar o componente discricionário da conta específica sob análise;

- Estimação e análise da relação entre um item específico como por exemplo a PCLD e o resultado contábil (lucro líquido), tendo em vista a identificação de possível uso na suavização de resultados, como desenvolvido por Fuji (2004).

De acordo com Fuji (2004) e Xavier (2007) a adequada formação da PCLD é de extrema importância para a saúde financeira das instituições financeiras. Isso porque a PCLD representa o dimensionamento do risco da principal fonte de receita das instituições financeiras, as operações de credito. Segundo Goulart (2007) existem indícios em vários estudos de que bancos com bom desempenho corrente e mau desempenho futuro esperado estocam lucros para o futuro pela redução do lucro corrente por meio da PCLD. Já no caso de instituições com mau desempenho corrente e bom desempenho futuro esperado existem evidências de empréstimos de lucros do futuro pelo aumento do lucro corrente por meio da PCLD. Este tipo de prática de suavização de resultados é conseguido pelos gestores através do uso de accruals discricionários.

É interessante notar que existem posicionamentos divergentes quanto às práticas de gerenciamento de resultados pelos gestores. Diversos estudos se fundamentam nas definições trazidas por Schipper (1989) e Healy e Wahlen (1999), que, em linhas gerais, colocam que o gerenciamento decorre de uma prática com a intenção de enganar os usuários da informação contábil sobre o desempenho da empresa. Por outro lado, há autores tais como Parfet (2000) e Arya, Glover e Sunder (2003), que propõem que gerenciar resultados é parte das atribuições dos gestores para reportar informações consistentes com o desenvolvimento dos negócios, isolando variações transitórias sobre 
o desempenho, que os usuários externos teriam dificuldade de fazer a partir da informação "pura" reportada.

São inúmeras as pesquisas sobre gerenciamento de resultados em instituições financeiras. Porém, o presente estudo destaca os principais estudos no âmbito brasileiro. O objetivo do trabalho de Fuji (2004) foi verificar se havia gerenciamento de resultados contábeis no contexto das instituições financeiras no Brasil, com foco na provisão para créditos de liquidação duvidosa, no período de 1999 a 2003. Os resultados do trabalho mostraram que havia indícios de Gerenciamento de Resultados por intermédio da PCLD, principalmente para minimizar a variação de resultados (alisamento de resultados).

Goulart (2007) investigou a utilização, pelas instituições financeiras em atuação no Brasil, da contabilização de operações de crédito, títulos e valores mobiliários (TVM) e derivativos para fins de Gerenciamento de Resultados, principalmente o alisamento de resultados. Os achados da pesquisa mostraram que o efeito de suavização ocorreu de forma mais forte em relação à PCLD. Xavier (2007) teve como objetivo verificar se bancos comerciais no Brasil utilizaram as provisões para créditos de liquidação duvidosa e outros elementos para gerenciar resultados no exercício de 2006. Os achados revelaram que cerca de $30 \%$ dos bancos analisados utilizavam a PCLD para gerenciar resultados.

Cunha et al. (2009) realizaram um estudo que visava identificar o gerenciamento de resultados contábeis em instituições financeiras do Brasil, por meio da conta de provisão para credito de liquidação duvidosa, que tiveram rodízio das empresas de auditoria independente no período de 2000 a 2007. Os resultados evidenciaram que no exercício em que existe a troca das empresas de auditoria independente o gerenciamento de resultado é amenizado em relação ao seu exercício anterior e com tendência de aumento no ano subsequente a troca da auditoria.

O trabalho de Dantas et al. (2013) procurou identificar se os bancos brasileiros são discricionários quanto às escolhas contábeis quando do reconhecimento e mensuração de derivativos para o gerenciamento de resultados, durante o período de 2002 e 2010. Os resultados revelaram que os bancos utilizam esse tipo de ação como mecanismo para o alisamento de resultados, e evidenciaram que essa prática é mais comum nas instituições privadas, com menores ativos e menor nível de capitalização. Além disso, os autores observaram que o uso da discricionariedade na mensuração do valor justo com derivativos com o propósito de alisamento de resultados é mais acentuado entre os bancos estrangeiros, contrariando o resultado de alguns estudos internacionais, onde a presença de capital estrangeiro é tida como indicador de melhor qualidade da informação contábil.

\section{METODOLOGIA}

O presente artigo pode ser classificado, de acordo com Vergara (2010), como descritivo e explicativo, visto que procura descrever e explicar a ocorrência de gerenciamento de resultados por meio da provisão para créditos de liquidação duvidosa (PCLD). Além disso, segundo Martins e Theóphilo (2009), tem foco empírico-positivista, já que apresenta técnicas de coleta, tratamento e análise de dados marcadamente quantitativos e onde a validação da prova científica é buscada através de testes dos instrumentos, graus de significância e sistematização das definições operacionais.

Foram analisados os dados contábeis das 50 maiores instituições financeiras com atuação no Brasil (considerando apenas os conglomerados financeiros, bancos comerciais e múltiplos e caixas econômicas), sob o critério de Ativo Total conforme classificação apresentada no site do Banco Central do Brasil (BCB). Optou-se pela coleta dos dados destas 50 maiores instituições financeiras diretamente das demonstrações contábeis semestrais ou do sítio do Banco Central, durante o período de 2006 a 2012, chegando-se inicialmente a 700 observações. Porém, foram excluídos da amostra os dados referentes aos bancos Rural, Cruzeiro do Sul, Panamericano e Schahin por terem sido identificadas fraudes contábeis em suas demonstrações durante o período analisado, bem como o BNDES, 
por particularidades inerentes à sua atividade. Também foram excluídos os bancos que não apresentaram valor de operações de crédito. Após os ajustes realizados, a amostra passou a contar com 639 observações. No Anexo 01, apresenta-se uma listagem com os bancos participantes da amostra final.

Foram utilizadas informações semestrais de 2006 a 2012 sobre o valor das despesas com provisão para créditos de liquidação duvidosa (PCLD), sobre o valor do ativo total (AT), sobre o valor de operações de crédito e arrendamento mercantil (CRED), sobre o valor do lucro líquido (LL), sobre o valor do Imposto de Renda (IR), além da informação sobre capital nacional ou estrangeiro (ESTR). As informações de ESTR, AT e CRED foram obtidas do sítio do Banco Central, enquanto as informações de PCLD, LL e IR foram obtidas diretamente das demonstrações contábeis semestrais das instituições financeiras, sendo o LL e o IR da Demonstração de Resultados do Exercício (DRE) e a PCLD do Balanço Patrimonial (BP) e das Notas Explicativas (NE).

Para alcançar os objetivos traçados aplicou-se a análise de regressão com base em um modelo econométrico com dados em pooled, que procurou verificar a existência de relação estatisticamente significativa entre o resultado das instituições financeiras e o nível de provisão para créditos de liquidação duvidosa (PCLD). Além disso, por meio de uma dummy procurou-se controlar a influência do capital estrangeiro na relação entre o LL e a PCLD.

Para realização deste estudo, os dados referentes à despesa com provisão para créditos de liquidação duvidosa foram capturados diretamente das demonstrações divulgadas pelas instituições financeiras, uma vez que as informações divulgadas pelo BCB se referem ao resultado de provisão (combinação das contas de receita e despesa). No COSIF - Plano Contábil das Instituições do Sistema Financeiro Nacional, as contas de receita e despesa da PCLD são as seguintes: 71990307, 71990352, 71990400, 71990606, 81830309, 81830354, 81830402 e 81830608. As contas COSIF listadas iniciadas por "7" são todas de reversão, ou seja, despesas constituídas em semestres anteriores e revertidas no presente exercício, enquanto que as contas iniciadas por "8" tratam das despesas de PCLD do período. Desta forma, para realização do presente estudo, optou-se por trabalhar com as informações de despesa extraídas das Demonstrações de Resultado das instituições financeiras e não do sítio do BCB.

Neste trabalho foi utilizado o seguinte modelo econométrico adaptado de Fuji (2004) e Goulart (2007), conforme Equação 1.

$$
\operatorname{PCLD}_{\mathrm{i}, \mathrm{t}}=\beta_{0}+\beta_{1} \mathrm{LL}_{\mathrm{i}, \mathrm{t}}+\beta_{2} \mathrm{CRED}_{\mathrm{i}, \mathrm{t}}+\beta_{3} \mathrm{ESTR}^{*} \mathrm{LLi}_{\mathrm{i}, \mathrm{t}}+\varepsilon_{\mathrm{i}, \mathrm{t}}
$$

Em que,

$\beta_{0}$ é a constante (intercepto);

\section{Variável dependente}

$P C L D_{i, t}$ é a despesas com provisão para créditos de liquidação duvidosa (com base no grupo de contas COSIF - 8.1.8.30.30-9, 8.1.8.30.35-4, 8.1.8.30.40-2 e 8.1.8.30.60-8) da instituição i no semestre $t$ dividida pelo Ativo Total;

\section{Variáveis independentes}

$L L i, t$ é o resultado excluindo as despesas com PCLD e despesas com IR da instituição i no semestre $\mathrm{t}$ dividido pelo Ativo Total;

$C R E D_{i, t}$ são as operações de crédito e arrendamento mercantil (com base no grupo de contas COSIF - 1.6.0.00.00-1 e 1.7.0.00.00-0) da instituição i no semestre t dividido pelo Ativo Total. $E S T R_{i, t}$ é a variável dummy para capital, assumindo 1 para os bancos estrangeiros ou com participação de capital estrangeiro e assumindo 0 para os bancos nacionais. 
Alguns aspectos em relação às variáveis utilizadas merecem destaque. A variável CRED tem o objetivo de controlar a influência de todas as outras variáveis do modelo, visto que é natural a relação entre a provisão para créditos de liquidação duvidosa e o volume total de operações de crédito. No caso da variável LL tomou-se o cuidado de expurgar o efeito da PCLD no resultado. Isso porque o lucro líquido já está afetado pela provisão. Para tanto, utilizou-se como artifício expurgar o valor da PCLD e do IR (que também já está afetado pela provisão, visto que a PCLD é uma despesa dedutível para fins de tributação sobre o lucro) para apurar o lucro que deveria ser utilizado no modelo. Assim, o resultado que está sendo considerado para fins de análise é aquele observado antes da decisão de formação da provisão.

A utilização da dummy ESTR teve como objetivo comparar o comportamento dos bancos estrangeiros em relação aos bancos nacionais, no tocante ao uso da despesa de PCLD no gerenciamento de resultados. Ressalta-se que esta variável dummy está sendo utilizada de forma multiplicativa, ou seja, o capital estrangeiro está controlando a relação entre a PCLD e o LL, de forma que seja possível observar se o capital estrangeiro aumenta ou reduz os indícios de gerenciamento de resultados.

O argumento é de bancos com capital estrangeiro teriam menor propensão ao gerenciamento de resultados, ou seja, que teriam informações contábeis de maior qualidade. Este argumento foi apresentado no artigo de Holanda e Coelho (2013), que ressaltam que se pode admitir que características como a participação estrangeira no controle possam funcionar como incentivo para atender à demanda por informações contábeis de qualidade, elevando os custos relacionados ao fornecimento de resultados gerenciados. Além disso, Silva et al. (2014) também ressaltam que a exposição ao financiamento estrangeiro (neste caso, por meio de investimento estrangeiro direto) reduz a propensão ao gerenciamento de resultados. Além disso, Maria Jr, Maria e Vargas (2013) ressaltam que a participação de investidores institucionais nacionais impacta mais os índices de gerenciamento de resultados do que a participação de investidores estrangeiros.

Desta forma, espera-se que se houver indícios de gerenciamento de resultado com o uso da provisão para créditos de liquidação duvidosa, o sinal do coeficiente $\beta_{1}$ da variável LL será positivo e significativo. Além disso, se este gerenciamento for mais forte em bancos nacionais que a variável ESTR ${ }^{*} L L$ apresente coeficiente $\beta_{3}$ com sinal negativo e significativo. Por fim, por conta da relação natural entre as provisões para créditos de liquidação duvidosa espera-se que a variável CRED tenha coeficiente $\beta_{2}$ com sinal positivo e significativo.

No estudo foi empregada a análise de regressão com dados em painel (pooling) por meio do Método de Mínimos Quadrados Ordinário (MQO), com utilização do pacote estatístico Eviews versão 8. Para análise dos pressupostos da regressão utiliza-se teste de normalidade (teste de JarqueBera) e de homocedasticidade dos resíduos (teste de Breusch-Pagan-Godfrey). Em caso de problemas com a presença de resíduos heterocedásticos, aplica-se a correção de White para tornar os resultados robustos. Além disso, analisa-se a colinearidade pelo cálculo do FIV (Fator de Inflação da Variância), aceitando-se FIVs $<5,00$.

\section{APRESENTAÇÃO E ANÁLISE DOS RESULTADOS}

Os resultados da Tabela 01 mostram que a regressão como um todo é significativa, visto que o p-valor do teste $\mathrm{F}$ é inferior ao nível de significância de 1\%. Com isso, pode-se concluir que o comportamento das variáveis independentes é capaz de explicar pouco mais de $50 \%$ do comportamento da variável dependente.

Percebe-se, ainda, que o modelo apresenta problemas tanto de não normalidade quanto de heterocedasticidade dos resíduos. Isso porque os resultados dos p-valores dos testes de Jarque-Bera e de Breusch-Pagan-Godfrey são menores do que o nível de significância de 1\%. Porém, em relação ao pressuposto de normalidade, seguindo a indicação de Brooks (2002), como tem-se uma amostra grande (639 observações), pode-se relaxar o pressuposto de normalidade dos resíduos tendo-se 
como base o Teorema do Limite Central. Já em relação à homocedasticidade dos resíduos, utilizouse a correção de White para tornar os resultados robustos à heterocedasticidade. Todos os FIV's se mostraram inferiores a 5,00, sendo o maior valor igual a 1,33. Logo, não há problemas de colinearidade entre as variáveis independentes.

Tabela 01 - Resultados do Modelo de Regressão - Variável Dependente: PCLD.

\begin{tabular}{ccccc}
\hline Variável Explicativa & Coeficiente & Erro Padrão $^{*}$ & $\boldsymbol{t}^{*}$ & p-valor \\
\hline LL & 0,5129 & 0,0887 & 5,7802 & $<0,0001$ \\
CRED & 0,0160 & 0,0023 & 6,9021 & $<0,0001$ \\
ESTR ${ }^{*} L$ & 0,2659 & 0,0749 & 3,5507 & $<0,0001$ \\
C & $-0,0051$ & 0,0011 & $-4,5047$ & $<0,0001$ \\
\hline Infs. Adicionais & Valores & Infs. Adicionais & Valores \\
\hline $\mathrm{R}^{2}$ & 0,5374 & Breusch-Pagan-Godfrey (p-valor) & $<0,0001$ \\
F (p-valor) & $<0,0001$ & \multicolumn{2}{c}{ Jarque-Bera (p-valor) } & $<0,0001$ \\
\hline
\end{tabular}

Nota: ${ }^{*}$ Estimado com correção de White para heterocedasticidade.

Em relação ao coeficiente da variável CRED, percebe-se que o mesmo apresenta sinal positivo e significativamente diferente de zero, ao nível de significância de $1 \%$. Isso quer dizer que, conforme esperado, um aumento do volume de operações de crédito e arrendamento mercantil explica um aumento nas provisões para créditos de liquidação duvidosa. Já em relação à variável LL, que representa o principal foco deste estudo, percebe-se que o coeficiente se mostrou significativo e com sinal positivo. Neste caso, existem indícios de que a formação da provisão para créditos de liquidação duvidosa esteja sendo explicada pelo nível de lucro. Isso porque a PCLD se mostra maior em instituições financeiras que apresentam maiores valores para o lucro antes da PCLD e do IR e se mostra menor em instituições que apresentam menores valores para o lucro antes da PCLD e do IR.

Isso está mostrando que quando uma instituição financeira verifica que seu lucro antes da PCLD e do IR é mais alto existe a tendência de aumento da provisão para créditos de liquidação duvidosa. Porém, quando o resultado antes da PCLD e do IR está mais baixo as instituições financeiras tendem a provisionar menos. Este possível comportamento é justificado por motivações de gerenciamento de resultados por meio do alisamento dos resultados em que se busca a estabilidade e constância do lucro.

Estes resultados confirmam os achados de Fuji (2004) de que há indícios de Gerenciamento de Resultados pelas instituições financeiras por intermédio da PCLD, principalmente para minimizar a variação de resultados (alisamento de resultados). Além disso, conforme Goulart (2007) os resultados também mostram o efeito de suavização nos resultados por meio do uso da PCLD. Também, da mesma forma que Xavier (2007) e Cunha et al. (2009), observou-se que as instituições financeiras utilizam a PCLD para gerenciar resultados.

Em linhas gerais, em concordância com as palavras de Fuji (2004) os resultados revelam que quando os lucros estão um pouco acima ou abaixo do que têm sido ao longo do tempo ou do alvo/planejado, os gestores tendem a suavizar os resultados, ou seja, reduzir a volatilidade de lucros. Além disso, em alinhamento com o que foi descrito por Goulart (2007) os resultados mostram que no caso de operações de crédito, quando o lucro (excluído o efeito da despesa de PCLD) aumenta, tem-se a PCLD atuando no sentido de reduzi-lo; se o lucro cai, existe a tendência de postergar o registro de provisões, de maneira que a PCLD impacte o resultado de forma menos adversa no presente; cumprindo-se, assim, o papel de suavização do resultado contábil. Por fim, ainda em consonância com os achados de Goulart (2007) os resultados indicam que, por meio do uso de accruals discricionários e específicos, existem indícios de que bancos com bom desempenho corrente e mau desempenho futuro esperado estocam lucros para o futuro pela redução do lucro corrente por meio 
da PCLD. Já no caso de instituições com mau desempenho corrente e bom desempenho futuro esperado existem evidências de empréstimos de lucros do futuro pelo aumento do lucro corrente por meio da PCLD.

Como dito anteriormente, para complementar a análise de indícios de gerenciamento de resultados adicionou-se uma variável que controlou a origem do capital: nacional ou estrangeiro. Os resultados observados para a variável ESTR (presença de capital estrangeiro) contrariam os resultados esperados, pois conforme destacado anteriormente tinha-se a expectativa de que o capital estrangeiro pudesse reduzir os incentivos ao gerenciamento de resultados, conforme indicado por Holanda e Coelho (2013) e Silva et al. (2014).

Porém, os resultados encontrados mostram que os bancos com capital estrangeiro possuem uma relação maior entre a PCLD e o desempenho (Lucro). Isso indica que existem indícios de maiores práticas de gerenciamento de resultados com o uso da PCLD em bancos com capital estrangeiro. Este resultado vai ao encontro dos achados de Dantas et al. (2013), que também encontraram maiores indícios de prática de gerenciamento de resultados em bancos com controle estrangeiro do que com controle nacional.

Isso pode estar mostrando que as pressões das matrizes estrangeiras pelo alcance de resultados planejados podem reforçar o comportamento de alisamento de resultados. Ou seja, os gestores das instituições financeiras com capital estrangeiro podem estar sendo incentivados a reduzir mais os resultados por meio do aumento da PCLD em períodos em que os mesmos se apresentem superiores ao planejado e a reduzir menos os resultados por meio da redução da PCLD em períodos em que os mesmos se apresentem inferiores aos resultados. Se a variação de resultados acontecer em períodos subsequentes existe ainda a possibilidade de reversão ou complementação da PCLD, que simplesmente acerta num período seguinte a provisão para créditos de liquidação duvidosa do ano anterior.

Além disso, conforme apresentado por Maria Jr, Maria e Vargas (2013) a conjectura de que os custos de monitoramento incorridos por investidores nacionais são menores do que os custos dos investidores estrangeiros poderia fazer com que instituições com capital nacional apresentassem menor propensão a se envolver em comportamento corporativo indesejável, como o gerenciamento de resultados, por exemplo.

\section{CONCLUSÕES E CONSIDERAÇÕES FINAIS}

O presente estudo teve como objetivo analisar os indícios de gerenciamento de resultados em instituições financeiras atuantes no Brasil no período de 2006 a 2012, por meio do uso da provisão para créditos de liquidação duvidosa (PCLD), com a finalidade de alisamento de resultados. Para tanto, utilizou-se um modelo econométrico que visa analisar a relação entre a PCLD e o nível de operações de crédito, o lucro antes da PCLD e IR e a presença de capital estrangeiro. No modelo utilizado, a observação de uma relação positiva e significativa entre a PCLD e o LL indica a possibilidade de gerenciamento de resultados para alisamento do resultado. Já uma relação negativa e significativa entre a PCLD e a ESTR indica que em instituições nacionais existe uma relação mais forte entre a PCLD e o LL, mostrando que o capital estrangeiro reduz os incentivos ao gerenciamento de resultados.

Em relação à variável CRED, os resultados econométricos mostram uma relação positiva e significativa entre esta variável independente e a PCLD. O uso desta variável é muito importante, pois existe uma relação natural entre o volume de operações de crédito e o nível de provisões para créditos de liquidação duvidosa. Isso porque a PCLD, de acordo com Fuji (2004) e Xavier (2007) é de extrema importância para a saúde financeira das instituições financeiras, já que a PCLD representa o dimensionamento do risco da principal fonte de receita, as operações de credito. 
Já no que diz respeito ao LL (lucro líquido expurgado o efeito da PCLD e do IR), os resultados indicam uma relação positiva e significativa entre o LL e a PCLD. Este resultado mostra que existem indícios de gerenciamento de resultados pelo uso da PCLD para que se obtenha o alisamento de resultados. Ou seja, os resultados indicam que as instituições financeiras do presente estudo tendem a aumentar a provisão para créditos de liquidação duvidosa quando apresentam resultado antes da PCLD e do IR maiores e tendem a reduzir a provisão para créditos de liquidação duvidosa quando estão com resultado antes da PCLD e do IR menores. Em outras palavras, a formação da provisão não só depende do volume de operações de crédito, mas também depende da situação de desempenho da instituição financeira, visando não mostrar resultados muito maiores ou menores do que os resultados de anos anteriores ou resultados planejados.

Estes achados estão em consonância com os resultados de outros estudos, tais como Fuji (2004), Goulart (2007), Xavier (2007) e Cunha et al. (2009). Em linhas gerais, quando o lucro (excluído o efeito da despesa de PCLD) aumenta, tem-se a PCLD atuando no sentido de reduzi-lo; se o lucro cai, existe a tendência de postergar o registro de provisões, de maneira que a PCLD impacte o resultado de forma menos adversa no presente; cumprindo-se, assim, o papel de suavização do resultado contábil por meio da redução da volatilidade dos lucros. Assim sendo, bancos com bom desempenho corrente e mau desempenho futuro esperado estocam lucros para o futuro pela redução do lucro corrente por meio do aumento da PCLD e instituições com mau desempenho corrente e bom desempenho futuro esperado usam lucros do futuro pelo aumento do lucro corrente por meio da redução da PCLD.

Por fim, em relação ao capital estrangeiro ou nacional, os resultados mostram que os bancos com capital estrangeiro possuem uma relação maior entre a PCLD e o desempenho (Lucro). Isso indica que existem indícios de maiores práticas de gerenciamento de resultados com o uso da PCLD em bancos com capital estrangeiro. Estes resultados contrariam, a princípio, os resultados esperados, visto que se tinha a expectativa de que o capital estrangeiro pudesse reduzir os incentivos ao gerenciamento de resultados, conforme indicado por Holanda e Coelho (2013) e Silva et al. (2014).

Este resultado vai ao encontro dos achados de Dantas et al. (2013) e Maria Jr, Maria e Vargas (2013). Isso pode estar indicando que os custos de monitoramento incorridos por investidores nacionais são menores do que os custos dos investidores estrangeiros, fazendo com que instituições com capital nacional apresentassem menor propensão ao gerenciamento de resultados. Além disso, reforçando este argumento os gestores das instituições financeiras com capital estrangeiro, por conta de maior pressão das matrizes e por conta de problemas de agência causados pelo distanciamento entre a propriedade e a gestão, que facilitam o comportamento oportunísticos dos gestores, podem estar sendo incentivados a reduzir mais os resultados por meio do aumento da PCLD em períodos em que os mesmos se apresentem superiores ao planejado e a reduzir menos os resultados por meio da redução da PCLD em períodos em que os mesmos se apresentem inferiores aos resultados planejados.

Por fim, como o presente trabalho não teve o objetivo de esgotar a discussão deste tema no Brasil, para estudos futuros, pode-se controlar alguns efeitos que não foram foco da presente pesquisa, tais como:

(i) A internacionalização do padrão contábil no Brasil, que pode ter efeito na qualidade da informação contábil;

(ii) O nível de qualidade do crédito em adição ao nível de operações de crédito;

(iii) O efeito ano, em virtude de crises financeira e aspectos econômicos (comportamento do PIB e/ou da taxa de juros e/ou de restrições ao crédito) que deveriam ter impacto na qualidade do crédito;

(iv) O uso da PCLD com fins regulatórios, principalmente para que as instituições financeiras possam alcançar limites solvência; 
(v) A diferença entre instituições financeiras de capital aberto e de capital fechado, em virtude dos problemas de agência entre controle e gestão;

(vi) O impacto do controle de capital, em função de empresas familiares e não familiares e do nível de concentração acionária;

(vii) O impacto da governança corporativa sobre o comportamento oportunísticos dos gestores das instituições financeiras;

(viii) A relação entre a persistência dos lucros e o uso do alisamento de resultados para reduzir a volatilidade;

(ix) O impacto de aspectos relacionados com a auditoria, tais como a escolha do auditor, o rodízio de auditoria e a existência de comitê de auditoria;

(x) A análise do erro de estimação da PCLD, por meio da análise das reversões e complementações em exercício(s) posterior(es). Percebe-se, assim, que mesmo com a contribuição do presente estudo reforçando a existência de indícios de gerenciamento de resultados pelas instituições financeiras atuantes no Brasil e mostrando o impacto do capital estrangeiro na busca pelo alisamento de resultados, ainda há muito a ser explorado do tema no ambiente brasileiro.

\section{REFERÊNCIAS}

ALMEIDA, J. E. F. Qualidade da informação contábil em ambientes competitivos. Tese de Doutorado, Universidade de São Paulo, 2010. Disponível em: http://www.teses.usp.br.

ARYA, A.; GLOVER, J. C.; SUNDER, S. Are unmanaged earnings always better for shareholders? Accounting Horizons, Supplement, p. 111-116, 2003.

BALL, R.; BROWN, P. Ball and Brown (1968): A retrospective. The Accounting Review, v. 89, n. 1, p. 1-26, 2014.

BARTH, M. E.; LANDSMAN; W. R; LANG, M. H. International Accounting Standards and Accounting Quality. Journal of Accounting Research, v. 46, n. 3, p. 467-498, 2008.

BROOKS, C. Introductory econometrics for finance. Cambridge: Cambridge University Press, 2002.

CARDOSO, R. L. Regulação econômica e escolhas de práticas contábeis: evidências no mercado de saúde suplementar brasileiro. Tese de doutorado, Universidade de São Paulo, SP, Brasil, 2005.

COMITÊ DE PRONUNCIAMENTOS CONTÁBEIS (CPC). Pronunciamento conceitual basico: estrutura conceitual para a elaboração e apresentação das demonstrações contábeis. Brasília, DF, 2011.

CUNHA, P. R. C.; BEZERRA, F. A.; GUBIANI, C. A.; RENGEL, S. Gerenciamento de Resultados Contábeis em Instituições Financeiras: Uma Análise do Rodízio de Empresas de Auditoria Independente. In: Congresso Brasileiro de Custos, 16, 2009, Fortaleza. Anais... Fortaleza, ABCustos, 2009. CD-ROM.

DANTAS, J. A.; GALDI, F. C.; CAPELLETTO, L. R.; MEDEIROS, O. R. Discricionariedade na Mensuração de Derivativos como Mecanismo de Gerenciamento de Resultados em Bancos. Revista Brasileira Finanças, v. 11, n. 1, p. 17-48, 2013. 
DECOURT, R. F.; MARTINEWSKI, A. L.; PIETRO NETO, J. Existe Gerenciamento de Resultados nas Empresas com Ações Negociadas na BOVESPA? In: Congresso USP de Controladoria e Contabilidade, 7, 2007, São Paulo. Anais... São Paulo: EAC-FEA/USP, 2007. CD-ROM.

FUJI, A. H. Gerenciamento de resultados contábeis no âmbito das instituições financeiras atuantes no Brasil. Dissertação de Mestrado. Universidade de São Paulo, SP, Brasil, 2004.

GOULART, A. M. C. Gerenciamento de resultados contábeis em instituições financeiras no Brasil. Tese de Doutorado. Universidade de São Paulo, São Paulo, Brasil, 2007.

HAW, I.; HU, B.; HWANG, L.; WU, W. Ultimate Ownership, Income Management and Legal and Extra-Legal Institutions. Journal of Accounting Research, v. 42, n. 2, p. 423-462, 2004.

HEALY, P. M.; WAHLEN, J. M. A review of the earnings management literature and its implications for standard setting. Accounting Horizons, v. 13, n. 4, p. 365-383, 1999.

HOLANDA, A. P.; COELHO, A. C. D. Gerenciamento de Resultados e Estrutura de Propriedade: Evidências no Brasil. In: Congresso Nacional de Administração e Ciências Contábeis - AdCont, 4, 2013, Rio de Janeiro. Anais... Rio de Janeiro: PPGCC/UFRJ, 2013. CD-ROM.

MACHADO, M. A.; MACEDO, M. A. S.; MACHADO, M. R. Análise do Conteúdo Informacional da DVA no Mercado de Capitais Brasileiro. In: Congresso USP de Controladoria e Contabilidade, 11, 2011, São Paulo. Anais... São Paulo: EAC-FEA/USP, 2011. CD-ROM.

MARCIUKAITYTE, D.; PARK, J. C. Market Competition and Earnings Management, 2009. Disponível em SSRN: http://ssrn.com/abstract=1361905.

MARIA Jr, E.; MARIA, M. M. L.; VARGAS, L. H. F. A Relação entre Investidores Institucionais, Gerenciamento de Resultados e Governança Corporativa. In: Congresso Nacional de Administração e Ciências Contábeis - AdCont, 4, 2013, Rio de Janeiro. Anais... Rio de Janeiro: PPGCC/UFRJ, 2013. CD-ROM.

MARTINEZ, A. L. Gerenciamento dos Resultados Contábeis: estudo empírico das companhias abertas brasileiras. Tese de Doutorado, FEA/USP, São Paulo, 2001.

MARTINEZ, A. L. Detectando earnings management no Brasil: estimando os accruals discricionários. Revista Contabilidade E Finanças, v. 19, n. 46, p. 7-17, 2008.

MARTINS, G. A.; THEÓPHILO, C. R. Metodologia da Investigação Científica para Ciências Sociais Aplicadas. 2 ed. São Paulo: Atlas, 2009.

MATSUMOTO, A. S.; PARREIRA, E. M. Uma pesquisa sobre o Gerenciamento de Resultados Contábeis: causas e consequências. Revista Contabilidade, Gestão e Governança, Brasília, v. 10, n. 1, p. 141157, jan./jun. 2007.

OLIVEIRA, V. A.; LEMES, S.; ALMEIDA, L. C. F.; FERREIRA, L. S. Gerenciamento de resultados contábeis por meio de ativos fiscais diferidos. Revista Contabilidade, Gestão e Governança, Brasília, v. 11, n. 1-2, p.153-169, jan./dez. 2008. 
PAULO, E.; MARTINS, E.; CORRAR, L. J. Detecção do gerenciamento de resultados pela análise do diferimento tributário. Revista de Administração de Empresas - RAE, São Paulo, vol. 47, n. 1, jan./mar. 2007.

PARFET, W. U. Accounting subjectivity and earnings management: A preparer perspective. Accounting Horizons, v. 14, n. 4, p. 481-488, 2000.

PAULO, E. Manipulação das Informações Contábeis: uma análise teórica e empírica sobre os modelos operacionais de detecção de gerenciamento de resultados. Tese de doutorado, Universidade de São Paulo, SP, Brasil, 2007.

RODRIGUES, A. Gerenciamento da informação contábil e regulação: evidências no mercado brasileiro de seguros. Tese de Doutorado, Universidade de São Paulo, SP, Brasil, 2008.

SCHIPPER, K. Commentary on earnings management. Accounting Horizons, v. 3, n. 4, p. 91-102, 1989.

SILVA, A. F.; WEFFORT, E. F. J.; FLORES, E. S.; SILVA, G. P. Earnings Management and Economic Crises in the Brazilian Capital Market. Revista de Administração de Empresas - RAE, v. 54, n. 3, p. 268-283, 2014.

VERGARA, S. C. Projetos e relatórios de pesquisa em administração. 12. ed. São Paulo: Atlas, 2010.

XAVIER, P. H. M. Gerenciamento de Resultados por Bancos Comerciais no Brasil. Tese de Doutorado, Universidade de São Paulo, SP, Brasil, 2007.

YAMAMOTO, M. M.; SALOTTI, B. M.. Informação Contábil: Estudos sobre a sua Divulgação no Mercado de Capitais. São Paulo: Atlas, 2006. 
ANEXO

Anexo 01 - Lista dos bancos presentes na amostra.

\begin{tabular}{|l|l|}
\hline \multicolumn{2}{|c|}{ BANCOS } \\
\hline ABC-BRASIL & CITIBANK \\
\hline ABN AMRO & CLASSICO \\
\hline ALFA & CREDIT AGRICOLE \\
\hline BANCOOB & CREDIT SUISSE \\
\hline BANESE & DAYCOVAL \\
\hline BANESTES & DBB BM \\
\hline BANIF & DEUTSCHE \\
\hline BANKBOSTON & DRESDNER \\
\hline BANPARA & FIBRA \\
\hline BANRISUL & GE CAPITAL \\
\hline BANSICREDI & HSBC \\
\hline BARCLAYS & IBIBANK \\
\hline BASA & INDUSTRIAL DO BRASIL \\
\hline BB & INDUSVAL \\
\hline BBM & ING \\
\hline BCO BVA S.A. & ITAU \\
\hline BCO COOPERATIVO SICREDI S.A. & J,MALUCELLI \\
\hline BCO DAYCOVAL S.A & JOHN DEERE \\
\hline BCO DO EST. DE SE S.A. & JP MORGAN CHASE \\
\hline BCO DO EST. DO PA S.A. & MERCANTIL DO BRASIL \\
\hline BCO DO NORDESTE DO BRASIL S.A. & MERRILL LYNCH \\
\hline BCO JOHN DEERE & MORGAN STANLEY \\
\hline BCO RABOBANK INTL BRASIL S.A. & NOSSA CAIXA \\
\hline BCO TOKYO-MITSUBISHI BM S.A. & ORIGINAL \\
\hline BESC & PACTUAL \\
\hline BGN & PINE \\
\hline BIC & RABOBANK \\
\hline BMC & SAFRA \\
\hline BMG & SAFRA \\
\hline BNB & SANTANDER \\
\hline BNP PARIBAS & SOCIETE GENERALE \\
\hline BONSUCESSO & SOFISA \\
\hline BRADESCO & SS \\
\hline BRB & UBS PACTUAL \\
\hline BTG PACTUAL & UNIBANCO \\
\hline BTMUB & VOTORANTIM \\
\hline BVA & WESTLB \\
\hline CEF & \\
\hline
\end{tabular}

